\title{
The Role of Faith in Work, Religious Beliefs, and Spirituality in the Prediction of Job Satisfaction Among Rehabilitation Experts
}

\author{
Yasser Rezapour ${ }^{1}$, Hossein Rezai ${ }^{2 *}$, Seyed Ali Hosseini ${ }^{3}$, Mohammad Taghi Mohseni Takalu
}

1. Department of Counseling, Faculty of Psychology and Educational Sciences, Ardakan University, Ardakan, Iran.

2. Musculoskeletal Rehabilitation Research Center, Ahvaz Jundishapur University of Medical Sciences, Ahvaz, Iran.

3. Department of Occupational Therapy, University of Social Welfare and Rehabilitation Sciences, Tehran, Iran.

\begin{tabular}{|c|c|}
\hline $\begin{array}{l}\text { Use your device to scan } \\
\text { and read the article online }\end{array}$ & ditation: Rezapour Y, Rezai H, Hosseini SA, Mohseni Takalu MT. The Role of Faith in Work, Religious Beliefs, and Spiri- \\
\hline 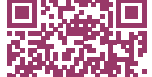 & $\begin{array}{l}\text { tuality in the Prediction of Job Satisfaction Among Rehabilitation Experts. Iranian Rehabilitation Journal. 2016; 14(4):217-222. } \\
\text { https://doi.org/10.18869/nrip.irj.14.4.217 }\end{array}$ \\
\hline astipis: & dol : https://doi.org/10.18869/nrip.irj.14.4.217 \\
\hline
\end{tabular}

Article info:

Received: 14 Jun. 2016

Accepted: 08 Oct. 2016

Keywords:

Spirituality, Religion, Rehabilitation, Speechlanguage pathology, Occupational therapy, Job satisfaction.

\section{A B STRACT}

Objectives: Integration of religion and spirituality in the workplace help people to be more satisfied with their job. The aim of the present study was to explore the role of religious beliefs, faith at work, and spirituality in the prediction of job satisfaction among rehabilitation experts.

Methods: With the help of simple random sampling, 163 subjects (74 speech and language pathologists, and 89 occupational therapists) were selected from rehabilitation experts employed across educational clinics affiliated to the Tehran University of Medical Sciences. The Islamic religiosity scale, faith at work scale, spirituality and spiritual care rating scale, and Dunnett's job satisfaction questionnaire were used to collect the data. Multiple regression and Pearson correlation were applied for data analysis.

Results: The findings showed that religious beliefs and faith at work can significantly influence job satisfaction among rehabilitation experts $(\mathrm{P}<0.05)$. However, spirituality did not have the same effect $(\mathrm{P}>0.05)$.

Discussion: These findings showed that religious beliefs are superior to spirituality as far as predictions about job satisfaction were concerned among Iranian rehabilitation experts.

\section{Introduction}

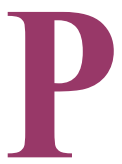

revious studies had predicted increasing changes in the working of organizations in the $21^{\text {st }}$ century and that employees have become more sensitive to their job. Also, spiritual and psychological fulfill- ment have attained a position of higher importance than financial fulfillment with regard to job satisfaction [1]. Integration of religion and spirituality in the workplace help people to be more satisfied with their job. Because of this integration, organizations with moral and spiritual employees have more financial investment [2]. Most employees find meaning in work by relying on religious

\section{* Corresponding Author:}

Hossein Rezai, MSc.

Address: Musculoskeletal Rehabilitation Research Center, Ahvaz Jundishapur University of Medical Sciences, Golsetan Blvd., Ahvaz, Iran.

Tel: +98 (611) 3743101

E-mail: rezai-h@ajums.ac.ir 
beliefs and have higher motivation for working [3]. The findings of a study showed that Iranian nurses considered taking care of patients as a way of worshipping God and believed that this would lead God to guide them in their own life. In this survey, the religious nurses showed a greater motivation for work and obtained higher job satisfaction because they considered their job as a divine assignment [4].

Religion is a school of thought including a set of beliefs, moralities, and rules that aim to guide humankind to happiness [5]. Religion ensures the existence of life hereafter and defines the purpose of life [6]. Spirituality is, however, a powerful inspirational force for searching the meaning of life, a deeper understanding of life values, appreciating the universe's magnitude; it is also a system of personal beliefs [7]. Although spirituality and religion are considered as independent, especially in Western cultures, [8] findings show a greater similarity than difference between these two variables. Searching for holiness is the most important connection between religion and spirituality [9].

Even though many studies in the West emphasize the distinction between religion and spirituality [8], it seems that spirituality is rooted in Islamic and religious instructions in Iran [11] based on the socio-cultural context of Iranian society and in accordance with Islamic teachings [10]. Religion and spirituality are not separable for most people in Iran. Indeed, religion is a source of spirituality, and Iranian people find spirituality by practicing their religious beliefs.

"Faith and spirituality at work" is a new and understudied subject that was recently introduced in psychology and organizational management [9]. Only a limited number of studies have investigated the role of spirituality in workplaces across Iran [12-14]. Unlike Western societies, there is no distinction between religion and spirituality in Iran [10]. Moreover, cultural differences may influence the relationship among religion, spirituality, and different aspects of an individual's job [2]. In comparison with other employees, religious beliefs and spirituality may influence job satisfaction and job performance of rehabilitation experts to a greater degree [3, 4]. The aim of this study was to investigate the role of religious beliefs, faith at work, and spirituality in the prediction of job satisfaction among rehabilitation experts. The following hypotheses were proposed for this study: Hypothesis 1 - Religiosity can significantly predict job satisfaction among rehabilitation experts; Hypothesis 2 - Faith at work can significantly predict job satisfaction among rehabilitation experts; and Hypothesis 3 - Spiri- tuality can significantly predict job satisfaction among rehabilitation experts.

\section{Methods}

\section{Participants}

The population of the present study included all 800 rehabilitation experts (speech and language pathologists and occupational therapists) employed in educational clinics affiliated to the Tehran University of Medical Sciences. With the help of simple random sampling, 163 subjects (74 speech and language pathologists and 89 occupational therapists) were selected from this population. From the list of employees of each clinic, some rehabilitation experts were selected by random sampling. Those who discarded the idea of participating in the study were replaced by randomly selected subjects who met the qualification criteria. The sample size of the study was determined by applying the Morgan and Krejcie table [15].

\section{Instruments}

\section{Islamic Religiosity Scale (IRS)}

This scale was developed by Bahrami Ehsan (2003) to evaluate religious beliefs based on the dominant religious structure of Iran. The primary form of this scale consisted of 64 items and 4 subscales including religiosity, religious disorganization, religious pretentiousness, and hedonism. Scores were recorded on the basis of a five-point Likert scale. The content validity of the scale was approved by experienced experts, and the questionnaire had convergent validity with similar questionnaires. The scale's Cronbach alpha ranged between 0.91 and 0.85 [16].

\section{Faith at Work Scale (FWS)}

This scale included 15 items, which were rated using a 5-point Likert scale. It was developed by reviewing religious maturity, religious attitudes, and relationship of religious beliefs with job performance. They differentiated religion and faith and developed this scale based on the role of religion in the workplace. This scale evaluated the role of faith in God and religious beliefs while performing work and accomplishing work duties. Lin et al showed that the scale had an acceptable internal consistency and reported that its Cronbach's alpha coefficient was 0.77 . It also had convergent validity with the Faith Maturity Scale [17]. In the present investigation, Cronbach's alpha of for FWS Scale was 0.86 . 
Spirituality and Spiritual Care Rating Scale (SSCRS)

This scale included 15 items, which were rated on a five-point Likert scale [18]. The developers of this scale believed that spirituality and spiritual care are distinct but overlapping entities and hence, should be evaluated by a single scale. This scale contained two sections. Section one covered the dimensions of spirituality including hope, meaning and purpose, forgiveness, beliefs and values, relationships, faith in God, and moralities. Section two included questions concerning spiritual care and considerations such as patient privacy and confidentiality, performing religious practices and offering care by way of kindness that are important to rehabilitation experts. For standardization of SSCRS in Iran, 10 Iranian professors evaluated and approved its content validity. The Persian version of SSCRS is of acceptable retest reliability [19]. Although the participants completed the entire questionnaire in the study, we only analyzed the subscale of spirituality. For the current study, Cronbach's alpha coefficient of this scale was 0.87 .

\section{Dunnett's Job Satisfaction Inventory}

This questionnaire was developed on the basis of Herzberg's motivation-hygiene theory of job satisfaction [20]. It contained 36 items, and the respondent's degree of agreement was recorded via a 7 point rating scale (where 1 is least agreement/lowest and 7 is most agreement/highest) [21]. Validity and reliability of this questionnaire were approved by one study [22].

\section{Results}

Based on the degree of skewness, the normal distribution of the data was verified and approved to ensure the application of regression analysis test.

Table 1 demonstrates the findings of Pearson correlation and multiple regression analysis. As indicated by correlation analysis, religious beliefs, faith at work, and spirituality are significantly correlated with job satisfaction of rehabilitation experts $(\mathrm{P}<0.01)$. Findings of regression analysis ( $\beta$ coefficient) showed that religious beliefs and faith at work can significantly predict the job satisfaction of rehabilitation experts $(\mathrm{P}<0.01)$. The beta coefficient of multiple regression of spirituality, however, was not significant, indicating that this variable cannot significantly predict the job satisfaction of rehabilitation experts $(\mathrm{P}>0.05)$.

\section{Discussion}

The result of regression analysis showed that religious beliefs and faith at work significantly predicted the job satisfaction of rehabilitation experts (Table 1). Based on the definition of faith at work provided by Lynn et al (2009), it seems that rehabilitation experts who believed in the existence of God in the workplace and that their job is a part of God's mission in their life experienced higher job satisfaction. In view of this, it appears that having religious beliefs enables rehabilitation experts to consider helping patients as a way of finding the meaning of life and gaining a higher job satisfaction. This finding was consistent with previous studies [3, 4, 23-28].

Organizational investigators have hypothesized that religiosity can directly predict job satisfaction $[29,30]$. They believe that relationship between job satisfaction and religiosity is based on the personality and values theory [31,32]. This theory suggests that religious beliefs become a part of the person's personality, and values imbue a positive influence on a person's performance including a rise in job satisfaction [30]. Religious beliefs may be more influential with regard to the performance of employees in assistive jobs (e.g. rehabilitation disciplines). In these jobs, religious employees think of helping others as a way of worshiping God and believe that their job is a divine assignment from God, who in turn will help them in their own life. That is why they

Table 1. Correlation and regression analysis of religious beliefs, faith at work, and spirituality to predict job satisfaction of rehabilitation experts.

\begin{tabular}{cccccc}
\hline Variables & Mean & Standard Deviation & Person Correlation with JS & $\boldsymbol{\beta}$ & P-Value \\
\hline Religious beliefs & 122.28 & 12.28 & $0.53^{*}$ & 0.26 & 0.038 \\
Faith at Work & 54.11 & 8.76 & $0.57^{*}$ & 0.42 & 0.000 \\
Spirituality & 55.37 & 5.34 & $0.50^{*}$ & 0.15 & 0.213 \\
Job Satisfaction (JS) & 165.19 & 38.70 & & \\
\hline
\end{tabular}

*Correlation is significant at the 0.01 level (2-tailed). 
may have higher levels of job satisfaction $[3,4]$. Studies have shown that people may use religion as a defense mechanism to cope with educational or job-related problems [33] and find meaning in their jobs, which lead them to obtain greater job satisfaction [28].

In testing the third study hypothesis, the findings of the current study demonstrated that spirituality cannot significantly predict the job satisfaction of rehabilitation experts. This is consistent with the finding of only one study [30] and is inconsistent with other studies $[24,25,27,28]$.

Probably one reason that spirituality could not significantly predict the job satisfaction of rehabilitation experts is the existence of a high correlation between spirituality and religious beliefs among Iranian Islamic people. Since religious beliefs were powerful predictors of job satisfaction, maybe the predictive effect of spirituality became a part of the predictive effect (or common variance) of the religious beliefs. This could be due to the high correlation between religion and spirituality in Iranian society [28]. Many Western investigators pointed out that religion is different from spirituality in Western societies [8, 34-36], but in other societies, especially in religious, Islamic societies such as Iran, it seems that there is no such difference $[10,11]$. Some studies conducted in Western societies, however, showed that many rehabilitation experts considered spirituality as an overlapping factor with religion $[37,38]$. We found no study that investigated the distinctive role of religion and spirituality in any aspect of a person's life (e.g. job satisfaction or mental health) in Iran. However, many Iranian investigators studied the impact of spirituality on job satisfaction and job performance of the people in the country without considering the distinction between religion and spirituality [12-14]. Instead of using the Islamic theoretical framework for the relationship between religion and spirituality in Islamic culture or including the religion factor in their studies, they relied on western models and methods in interpreting their findings [10].

Given the findings of the current study and considering the role of religion in the Iranian people's lives, it seems that offering religious instructions to rehabilitation experts can help them find meaning in their lives and gain greater job satisfaction. It is suggested that chiefs of rehabilitation centers provide a peaceful place for praying, encourage their employees to discuss religious matters at the workplace, employ a clergy for offering religious instructions to employees, and provide religious books to reinforce and enhance the religious beliefs of the rehabilitation experts [39].
One of the limitations of the current study is that the population of participants is limited to Iranian society. Since the relationship between religious beliefs and spiritualty may be different in other cultures, the generalization of the finding of the current study to other societies is uncertain. Moreover, since all participants of the current study were Muslims, generalizations of these findings to the rehabilitation experts belonging to other religious beliefs would be erroneous. Finally, further research is needed to better reveal the significance of these findings for other health occupations such as medicine, nursing, social work, and professional rescue.

\section{Acknowledgments}

This research did not receive any specific grant from funding agencies in the public, commercial, or not-forprofit sectors. We thank all the rehabilitation experts participated in the study. We are also immensely grateful to Mehdi Dorudgar for his comments on an earlier version of the manuscript that greatly improved the manuscript.

\section{Conflict of Interest}

The authors declared no conflict of interests.

\section{References}

[1] Hall DT. Protean Careers of the 21st Century. Academy of Management Perspectives. 1996; 10(4):8-16. doi: 10.5465/ ame.1996.3145315

[2] Geh E, Tan G. Spirituality at work in a changing world: Managerial and research implications. Journal of Management, Spirituality \& Religion. 2009; 6(4):287-300. doi: $10.1080 / 14766080903290093$

[3] Mirsaleh Y, Rezai H, Kivi S, Ghorbani R. The role of religiosity, coping strategies, self-efficacy and personality dimensions in the prediction of Iranian undergraduate rehabilitation interns' satisfaction with their clinical experience. Clinical Rehabilitation. 2010; 24(12):1136-43. doi: $10.1177 / 0269215510375907$

[4] Ravari A, Vanaki Z, Houmann H, Kazemnejad A. Spiritual job satisfaction in an Iranian nursing context. Nursing Ethics 2009; 16(1):19-30. doi: 10.1177/0969733008097987

[5] Habibi R. Religiosity and spirituality [Persian]. Journal of Hadise Zendegi 2003; 3(3):100-4.

[6] Tabatabaei M. [AL-mizan interpretation (Persian)]. Ghom: Jame Modaresin Publication; 2000.

[7] Cavanagh GF. Spirituality for managers: Context and critique. Journal of Organizational Change Management. 1999; 12(3):186-99. doi: 10.1108/09534819910273793 
[8] Zinnbauer BJ, Pargament KI. Religiousness and spirituality. In: Paloutzian RF, Park CL, editors. Handbook of the Psychology of Religion and Spirituality. New York: Guilford Press; 2005.

[9] Duffy RD, Reid L, Dik BJ. Spirituality, religion, and career development: implications for the workplace. Journal of Management. Spirituality \& Religion. 2010; 7(3):209-21. doi: 10.1080/14766086.2010.500004

[10] Roudgar MJ. [Spirituality in Quran: Fundamentals, dimensions and functions of Quran's spirituality (Persian)]. Pazhuhesh-haye E'teghadi-Kalami. 2009; 14(14):15-32.

[11] Etratdoust M. [Planning position in Islamic management in tradition and Quran verses (Persian)]. Police Human Development. 2010; 7(33):107-26.

[12] Lavassani MJ, Keyvanzade M, Arjmand N. [Spirituality, job stress, organizational commitment, and job satisfaction among nurses in Tehran (Persian)]. Journal of Contemporary Psychology. 2008; 3(2):61-73.

[13] Farhangi AA, Fatahi M, Vasegh B. [Workplace spirituality and its role in improving organizational citizenship behavior (Persian)]. Journal of Organizational Culture of Management 2006; 4(3):5-36.

[14] Ziyaei MS, Nargesiyan A, Aybaghi Esfahani S. [The role of spiritual leadership on human resource empowerment in the University of Tehran (Persian)]. Journal of Public Administration. 2008; 1(1):67-86.

[15] Krejcie RV, Morgan DW. Determining sample size for research activities. Educational and Psychological Measurement 1970; 30(3):607-10. doi: 10.1177/001316447003000308

[16] Bahrami EH, Tashk A. [Dimensions of the relationship between religiosity and mental health and evaluation of religiosity scale (Persian)]. Psychology \& Educational science. 2004; 34(2):41-63.

[17] Lynn ML, Naughton MJ, VanderVeen S. Faith at Work Scale (FWS): Justification, development, and validation of a measure of Judaeo-Christian religion in the workplace. Journal of Business Ethics. 2008; 85(2):227-43. doi: 10.1007/s10551008-9767-3

[18] McSherry W, Draper P, Kendrick D. The construct validity of a rating scale designed to assess spirituality and spiritual care. International Journal of Nursing Studies. 2002; 39(7):72334. doi: 10.1016/s0020-7489(02)00014-7

[19] Khoshknab MF, Mazaheri M, Maddah SS, Rahgozar M. [Iranian nurses attitude to spirituality and spiritual care (Persian)]. Payesh. 2008; 8(1):31-7.

[20] Herzberg F. Work and the nature of man. Cleveland, Ohio: World Publishing Company; 1966.

[21] Mousavi SS, Movahhedi Rad S. [The study of job satisfaction among nurses in Tehran military hospitals in 2014 (Persian)]. Nurse and Physician Within War. 2(5):183-85

[22] Dunnette MD, Campbell JP, Hakel MD. Factors contributing to job satisfaction and job dissatisfaction in six occupational groups. Organizational Behavior and Human Performance. 1967; 2(2):143-74. doi: 10.1016/0030-5073(67)90027-x

[23] Hsiao YC, Chien LY, Wu LY, Chiang CM, Huang SY. Spiritual health, clinical practice stress, depressive tendency and health-promoting behaviours among nursing students Journal of Advanced Nursing 2010; 66(7):1612-22. doi: 10.1111/j.1365-2648.2010.05328.x

[24] Clark L, Leedy S, McDonald L, Muller B, Lamb C, Mendez T, Kim S, Schonwetter R. Spirituality and job satisfaction among hospice interdisciplinary team members. Journal of Palliative Medicine 2007; 10(6):1321-8. doi: 10.1089/ jpm.2007.0035

[25] Ray SL, McGee D. Psychiatric nurses' perspectives of spirituality and spiritual needs during an amalgamation. Journal of Psychiatric and Mental Health Nursing. 2006; 13(3):330-6. doi: 10.1111/j.1365-2850.2006.00969.x

[26] Brown C. Low morale and burnout; Is the solution to teach a values-based spiritual approach?. Complementary Therapies in Nursing and Midwifery. 2003; 9(2):57-61. doi: 10.1016/ s1353-6117(03)00012-x

[27] Snir R, Harpaz I. Attitudinal and demographic antecedents of workaholism. Journal of Organizational Change Management. 2004; 17(5):520-36. doi: 10.1108/09534810410554524

[28] Milliman J, Czaplewski AJ, Ferguson J. Workplace spirituality and employee work attitudes: An exploratory empirical assessment. Journal of Organizational Change Management 2003; 16(4):426-47. doi: 10.1108/09534810310484172

[29] Grabhorn RA. A study of the relationship between job satisfaction and religious motivation using intrinsic and extrinsic dimension [PhD thesis]. Kansas: Kansas State University.

[30] Koberg CS, Chusmir LH. Relationship between sex role conflict and work-related variables: Gender and hierarchical differences. The Journal of Social Psychology. 1989; 129(6):779-91.

[31] Rokeach M. Belief, attitudes and values. San Francisco: Jossey-Bass Inc.; 1968.

[32] Martin DB. Personality: Effective and ineffective. Westport: Quorum Books; 1998.

[33] Constantine MG, Miville ML, Warren AK, Gainor KA, Lewis-Goles MEL. Religion, spirituality, and career development in African American college students: A qualitative inquiry. The Career Development Quarterly. 2006; 54(3):227-41 doi: 10.1002/j.2161-0045.2006.tb00154.

[34] Heelas P, Woodhead L, Seel B, Szerszynski B, Tusting K. The spiritual revolution: Why religion is giving way to spirituality. New Jersey: Wiley-Blackwell; 2004.

[35] Mitroff II, Mitroff IA, Denton EA. A spiritual audit of corporate America: A hard look at spirituality, religion, and values in the workplace. San Francisco: Jossey-Bass Publishers; 2012.

[36] Pargament KI. The Psychology of Religion and Spirituality? Yes and No. International Journal for the Psychology of Religion 1999; 9(1):3-16. doi: 10.1207/s15327582ijpr0901_2

[37] McSherry W, Cash K, Ross L. Meaning of spirituality: implications for nursing practice. Journal of Clinical Nursing. 2004; 13(8):934-41. doi: 10.1111/j.1365-2702.2004.01006.x

[38] Greasley P, Chiu LF, Gartland M. The concept of spiritual care in mental health nursing. Journal of advanced nursing 2001; 33(5):629-37. PMID: 11298199 
[39] Duerr M. The contemplative organization. Journal of Organizational Change Management. 2004; 17(1):43-61. doi: $10.1108 / 09534810410511297$ 